\title{
Partidos y sistemas de partidos: historias y políticas en Argentina, Brasil y Uruguay
}

Javier Bonilla Saus

UDI $\Lambda$, MÍXICO

\begin{abstract}
En este ensayo se hace un análisis comparativo basado en los artículos centrales y sus respectivos artículos críticos presentados en este número de Secuencia, con tres enfoques sobre la historia partidaria del siglo Xx en Argentina, Brasil y Uruguay. Las similitudes y diferencias políticas caracteristicas de los tres países están basadas en una comparación de las perspectivas históricas y de distintas concepciones políticas.
\end{abstract}

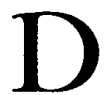

urante la última década, el interés de los análisis latinoamericanos en el tema de los partidos políticos $y$, más particularmente, en el estudio de los sistemas de partidos del continente, se ha ido incrementando de manera sustancial.

En efecto, desde fines de la década de los ochenta y principios de la actual, coincidiendo con el auge de la democratización en los países latinoamericanos que emergían de más de un decenio de autoritarismo, los análisis políticos están manifestando un marcado interés por los problemas vinculados a la consolidación de los regíme- nes democráticos en los países del continente. ${ }^{1}$ En ese sentido, la intención por enfrentar críticamente la emergencia de los obstáculos específicos de las experiencias latinoameri-

1 Ina muy rápida pero atinada kectura del tránsito del discurso revolucionario a la reivindicación democrática se encuentra en cl capítulo primcro: "De la revolución a la cemocracia" de Norbcrt I.cchner, Patios, 1990. A propósito de los avatares de la consolidación democrática, la bibliografia es hoy sumamente abundantc: véanse, por cjemplo, Barros llorcasitas, Hurtado y Pérc\% Fcrnándè, Jvansiciones, 1991; Mayorga, Democracia, 1992, y Cavaro\%ii, Más alla, 1989. 
canas de democratización y redemocratización, tiende a afirmarse mediante una doble tendencia.

Por un lado, el viejo acento "estatalista" ${ }^{2}$ que caracterizaba a los análisis políticos latinoamericanos en la década de los años setenta parece haberse mitigado, ${ }^{3}$ y cuando hoy nos interrogamos por el Estado latinoamericano contemporáneo y por sus relaciones con la democracia, las preguntas actuales se originan siempre a partir de un marcado interés "societal". En otras palabras, de lo que se trata hoy es más de perfeccionar los Estados latinoamericanos en el sentido de esa mayor democratización que las sociedades reclaman y no tanto rechazar frontalmente aquel carácter radicalmente "antidemocrático" que, a veces un tanto indiscriminadamente, se le asignaba hasta no hace muchos años. En esa perspectiva el Estado es cada vez más considerado hoy en América Latina como una construcción políti-

\footnotetext{
2 Por "estatalismo" designamos aquí la tendencia de los análisis políticos de la época a considerar al Estado como una estructura stuprasocial c impuesta a grandes sectores de la socicdad civil, en muchos casos como cfecto de la mécanica conómica. La bibliogralía sobre cl Fstado hatinoanncricano desde la década del sctenta cn adclante es amplísima. Como mero título de relerencias generales sobre las distintas modalidades de albordar cl análisis del Jistado en ese periodo recordemos Kaplan, formactón, 1969); Bambirra, Capilalismo, 1974; Cotler, Clases, 1978; Ianni, Populismo, 1970, y Percyra, "lestado", 1979.

3 Quizá cl texto que mejor exprese el ocaso de la preocupación "cstatalista" y la cmergencia del renovado interés por las potencialidactes transformadoras de ha socicdid civil en los análisis políticos latinoamericanos sca: Nun, Rebelion, 1988.
}

ca posible; como un resultado de la voluntad política de aquellos actores que influyen en su diseño y elaboración. Así, en lugar de seguir ocupando aquel papel hobbesiano de edificio institucional suprasocial e "intocable" en el que se encontraban depositados, en última instancia, los aspectos más permanentes y decisivos de la existencia nacional, el Estado latinoamericano comienza a perfilarse como una instancia que puede ser socialmente controlada. Quizá sea por ello que también, por vez primera en muchas décadas, el Estado latinoamericano aparece cada vez más claramente como una entidad "reformable" en función de las diversas necesidades que las sociedades y los procesos de democratización parecen requerir.

En una segunda dirección, y como corolario previsible de la adopción de esta nueva perspectiva de análisis, se ha puesto en el tapete la discusión sobre cuáles son los instrumentos políticos más adecuados para obtener -consolidar o, más radicalmente, profundizar- la democratización del Estado, del sistema político y, en general, de la gestión política de la sociedad civil en los países latinoamericanos.

En esta incursión en la búsqueda de los instrumentos aptos para encarar la tarea de democratización de la vida política de nuestras sociedades ha enraizado la preocupación contemporánea sobre los partidos políticos latinoamericanos. En efecto, de todos los instrumentos políticos tradicionales que la ciencia política moderna ha trabajado en Occidente, la institución "partido" quizá sea la más compleja, 
la más desarrollada y, por ello mismo, la más polémica. ${ }^{4}$

Embarcándose en la discusión sobre los partidos políticos y sobre los sistemas de partidos de América Latina como herramientas aptas para impulsar el proceso de democratización y posterior consolidación democrática, los estudios políticos latinoamericanos han concretado un giro de orientación doblemente significativo. Por un lado, y desde una perspectiva que podríamos llamar "ideológica", si los partidos políticos han de ser los sujetos privilegiados en la difícil tarea de la consolidación democrática latinoamericana, ello significa, por lo menos de una manera implícita y tendencial, que el pensamiento político del continente reconoce que no es éste el momento histórico para reivindicar las viejas formas políticas autoritarias - populismos movimientistas, populismos estatalistas, militarismos o tecnocratismos esclarecidos, etc.que han caracterizado por décadas a América Latina. Por el otro, y en lo referente a los distintos campos temáticos que este nuevo enfoque implica, resulta evidente que, en la actualidad, al menos uno de los ejes de los análisis sobre historia política de América Latina se orienta hacia la exploración de la historia $-o$, en los casos que así corresponde, hacia el estudio de la ausencia y de las razones de esa ausencia- de los partidos políticos latinoamericanos.

4 Un ejemplo del renovado interés por los partidos políticos, relativamentc tcmprano: Cavaro\%i y Garretón, Muev/e, 1989. Un scgundo cjcimplo de recicntc aparición: Dutrénit y Valdés (coords.), Iin, 1995.
En este texto de vocación esencialmente comparativa, y habida cuenta de que el lector interesado tendrá la posibilidad de referirse inmediatamente a los diferentes trabajos dedicados a cada uno de los tres casos nacionales aquí estudiados, nos hemos centrado en un intento de abordaje en torno a los distintos análisis de los sistemas de partidos que se incluyen en esta publicación. Para ello hemos organizado nuestro trabajo en torno a dos grandes ejes o perspectivas de análisis. Una primera perspectiva, que quizá de manera un tanto apresurada podríamos llamar "comparación metodológica", mediante la que se pretende esbozar simultáneamente las diferencias y similitudes de enfoque que caracterizan a las tres historias partidarias que subyacen implícita o explícitamente detrás de los trabajos considerados. Una segunda perspectiva, que de manera no menos provisoria podríamos llamar "teórica", intentará identificar las distintas concepciones de la política más o menos implícitas en los textos dedicados a los casos analizados.

\section{HISTORIAS}

Desde el punto de vista de las modalidades "metodológicas" del tratamiento de la cuestión partidaria vale la pena destacar, en primer término, la existencia de una convergencia general, aunque consistente, en la manera de abordar la problemática de los partidos políticos en cada uno de los países analizados. En efecto, los trabajos aquí analizados comparten por lo me- 
nos dos características que, para nosotros, constituyen virtudes comunes destacables.

La primera de estas virtudes tiene que ver con el hecho de que, en los distintos trabajos incluidos en esta publicación, los partidos políticos y los sistemas partidarios de Argentina, Brasil y Uruguay son, en los artículos presentados, considerados como productos históricos. Los defectos y las virtudes, las dificultades y los aciertos, los éxitos y los fracasos en el camino hacia la construcción de distintos tipos de sistemas de partidos van a ser presentados por los diferentes autores siempre como el resultado de un proceso que, ante todo, ha sido históricamente construido. Y aquí entendemos por "históricamente construido" la adopción de una perspectiva de análisis en la que los partidos y los sistemas de partidos son esencialmente el resultado de la interacción, a lo largo de los distintos periodos analizados, de una multiplicidad de sujetos políticos. Estos sujetos políticos, por otra parte, están pensados como sujetos que operan en ese amplio y problemático espacio que toda sociedad moderna concibe como definido entre la libertad y la determinación.

La preferencia por este enfoque histórico sobre otras posibles modalidades para abordar la cuestión de los sistemas partidarios de nuestros tres países tiene, en primer término, las no siempre bien apreciadas virtudes de un cierto realismo. En efecto, evitando la doble tentación - a veces bastante generalizada en algunos textos contemporáneos de las ciencias politicas- de internarse en los meandros de una teorización general sobre los partidos, los sistemas de partidos o la democracia ; o en la siempre recurrente tendencia a intentar generalizaciones un tanto abstractas sobre "la política en Latinoamérica", "los partidos políticos latinoamericanos" o "la democracia en América Latina", los análisis aquí considerados optan por abordar el estudio de las instituciones partidarias como tentativas de reconstrucción histórica que se resuelven en un terreno estrictamente nacional. No se trata, ni siquiera, de historias convergentes, de historias paralelas ni, menos aún, de "historias específicas" definidas como "vertientes nacionales" de algún tipo de tendencia continental que organizaría el devenir histórico partidario latinoamericano. Son historias rigurosamente autónomas y, como era previsible, estas tres historias políticas y partidarias difieren radicalmente entre sí.

Difieren, en primer término, porque remiten a tres historias nacionales distintas y, en segundo término y mucho más decisivamente, también difieren entre sí porque se trata de tres historias cuya construcción responde a dispositivos conceptuales para concebir la política -y, por ende, de manera implícita, a inquietudes de investigación-diferentes.

Además, como ya anunciamos más arriba, a pesar de estas saludables divergencias nuestras tres historias comparten un segundo atributo "metodológico" rescatable. En efecto, aunque se trata de historias diferentes, las tres son historias legítimamen- 
te políticas que, en contraste con una tradición latinoamericana que ha hecho del alegato sociologizante o del reduccionismo economicista -real o disfrazado- una suerte de lugar común de los análisis políticos del continente, aspiran a organizarse y explicarse preferentemente en el siempre difícil terreno del análisis estrictamente político. En ese sentido, aunque no están ausentes del análisis las trascendentales transformaciones económicas que Argentina, Brasil y Uruguay han sufrido en el último siglo, ni se pasan por alto las distintas modificaciones acontecidas en el seno de las estructuras sociales de estos países, no es menos cierto que los tres estudios manifiestan una preocupación constante por arraigar los respectivos análisis en el devenir específicamente político de cada uno de esos países y en los distintos intentos $-\mathbf{a}$ veces exitosos, a veces fallidos- de organización partidaria que dicho devenir comporta.

Esta voluntad de anclar políticamente el análisis histórico se manifiesta, en primer término, en el hecho de que los trabajos están fundados en periodizaciones políticamente construidas. En efecto, en todos los casos las secuencias de análisis de los sistemas partidarios de nuestros tres países se estructuran de acuerdo con una lógica estrictamente política y los intentos de periodización que pretenden soportarla tendrán siempre como ejes definitorios los acontecimientos políticos más significativos de la historia de cada país.

En segundo lugar, los sujetos privilegiados de estas tres historias partida- rias son, como era previsible, "los partidos políticos". Aunque las dificultades teóricas que resultan de la utilización generalizada de esta expresión para designar formas organizativas e ideológicas de representación política tan diversas como el Partido Colorado del Uruguay doctoral de fin del siglo XIX, el radicalismo argentino de las primeras décadas del $\mathrm{XX}$ o el varguismo de mediados de los años cuarenta en Brasil, no es menos cierto que las virtudes renovadoras de este protagonismo partidario en el análisis - por impreciso que éste resulte conceptualmente hablando, cuando se consideran todos los trabajos conjuntamente- son evidentes. Aunque en América Latina abundan las historias en las que los partidos políticos hacen acto de presencia, no son muchas las historias políticas latinoamericanas construidas, como es el caso aquí, "desde" el protagonismo del acontecer partidario o "a partir de los problemas" que la ausencia de este protagonismo genera.

1. La historia que nos ofrece Marcelo Cavarozzi es, en realidad, la historia de los reiterados fracasos al querer construir un sistema de partidos "normal" en Argentina durante el periodo anterior a $1983 . .^{5} \mathrm{El}$ periplo del autor se organiza en torno a la pregunta de hasta dónde los partidos políticos han sido relevantes en el marco de la his-

5 El término que empleamos se justifica cn la medida en que el usado por el autor para expresar la idca de que el sistema de partidos argentino no alcanza al menos hasta 1983 una modalidad de funcionamicnto regular, es cl de "sistema de partidos contranatura". 
toria política argentina, $y$ transcurre en el análisis de los obstáculos sucesivos que fueron postergando la necesaria maduración del sistema partidario. De 1983 en adelante, el texto se pregunta hasta qué punto se ha organizado efectivamente en ese país un sistema estable de partidos y en qué medida los partidos políticos han logrado transformarse en instrumentos idóneos para la consolidación democrática. El trabajo de Aníbal Viguera, por su parte, intenta señalar cómo, a pesar de que los partidos políticos argentinos constituyen una constante vigorosamente arraigada en la historia de ese país y una dimensión fundamental del funcionamiento político de la sociedad argentina, su incapacidad para evitar el juego de "exclusión recíproca" y, sobre todo, su larga inoperancia en la tarea de funcionar como espacios políticos de agregación y negociación de demandas e intereses de la sociedad civil, terminaron conspirando contra la consolidación definitiva de un sistema de partidos estable.

En el caso de Argentina, la historia partidaria se presenta escindida en dos grandes etapas claramente definidas: una primera que se inicia en 1912-1916 para finalizar en 1983 y una segunda que, desde ese momento hasta la fecha, pareceria indicar el principio de la plausible consolidación de un sistema de partidos estable. Todo el primer periodo se presenta como un recurrente intento de definir un funcionamiento sistemático de los partidos políticos que no logra nunca estabilizarse. Se trata entonces de un proceso de instauración, des- moronamiento y reinstauración de diferentes sistemas políticos sucesivos en los que los distintos partidos existentes no terminan nunca de consolidarse realmente, por lo que no debe sorprender que la historia propuesta sea, ante todo, y al menos en su primera parte, una historia de la inestabilidad política y partidaria de Argentina.

Asi, desde el inicio, un primer hito importante, cronológicamente designado por Cavarozzi mediante la referencia a la ley Sáenz Peña de 1912 y al triunfo de Hipólito Yrigoyen en 1916, aparece como un intento fallido de redefinición del horizonte ciudadano $y$ de establecimiento de un primer sistema de partidos organizado de acuerdo con una lógica liberal y democrática capaz de sobrepasar los límites del Estado oligárquico en crisis desde finales del siglo anterior. La profunda fragmentación del orden oligárquico y el inesperado -y quizá algo paroxístico- crecimiento del radicalismo opositor, significaron que el tránsito hacia un régimen político de corte democrático y dotado de partidos políticos estables se complicase rápidamente.

El golpe de Estado de 1930 constituye un segundo momento crucial en la historia de los partidos argentinos puesto que significará la derrota simultánea de las dos grandes tradiciones políticas que, en ese momento, resultaban relevantes en ese país: la tradición política liberal decimonónica que, al igual que en otras partes de América Latina, había acuñado el orden oligárquico del fin de siglo y la tradición reformista democratizante 


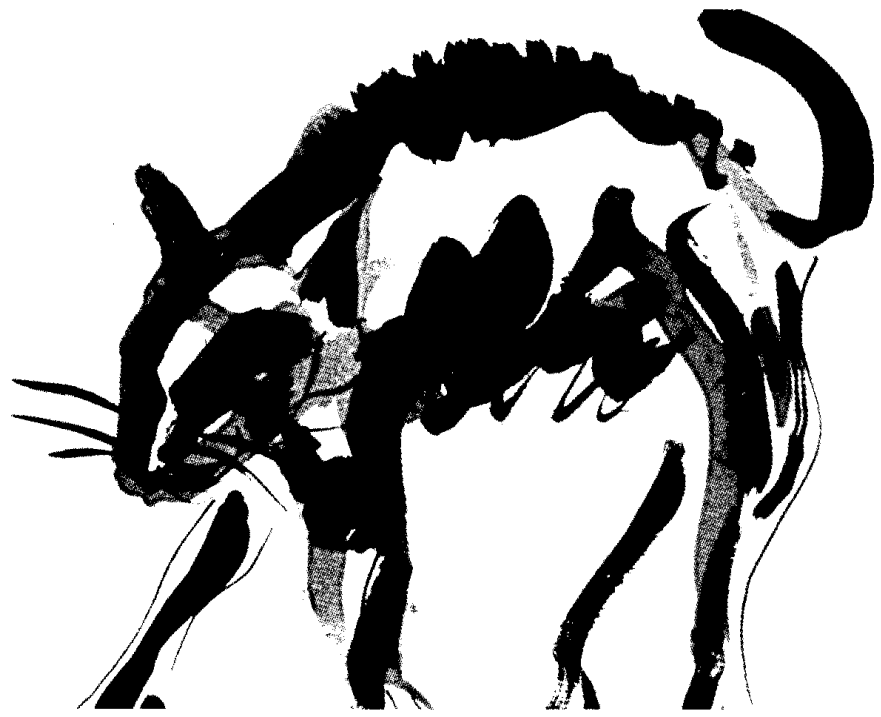

que, de 1890 en adelante, había pugnado por una redefinición del régimen político liberal en clave democrática. Cavarozzi señala adecuadamente que 1930 es un "hito que marcó el aborto de la democracia política argentina" y que "inauguró un periodo de más de medio siglo de inestabilidad institucional"; con ello, vale la pena agregar, Argentina abandonaría por largo tiempo la tradición política liberal y comenzaría su trágica travesía por los regímenes autoritarios de distinto signo.

La compleja historia partidaria argentina encontrará un tercer momento significativo en la coynuntura de los años 1943-1945 y la emergencia de Juan Domingo Perón. La restauración conservadora que siguió al golpe de
1930 fue más un simulacro de democracia que un verdadero retorno al orden liberal, y toda posibilidad de avanzar hacia el pluralismo político naufragó en manos de los partidos políticos del periodo 1930-1943 que oscilaron sistemáticamente entre las proscripciones oficiales o la exclusión y el desconocimiento recíprocos cuando lograban escapar de aquéllas. Como consecuencia, las modalidades de hacer política de los distintos actores cayeron en un profundo descrédito. Perón, atento a ello y simultáneamente consciente de que los espacios tradicionales donde se desplegaba esta política ("el cuartel" -terreno de los militares y del discurso conservador-y "el comité partidario" -espacio de afirmación del discurso radical) 


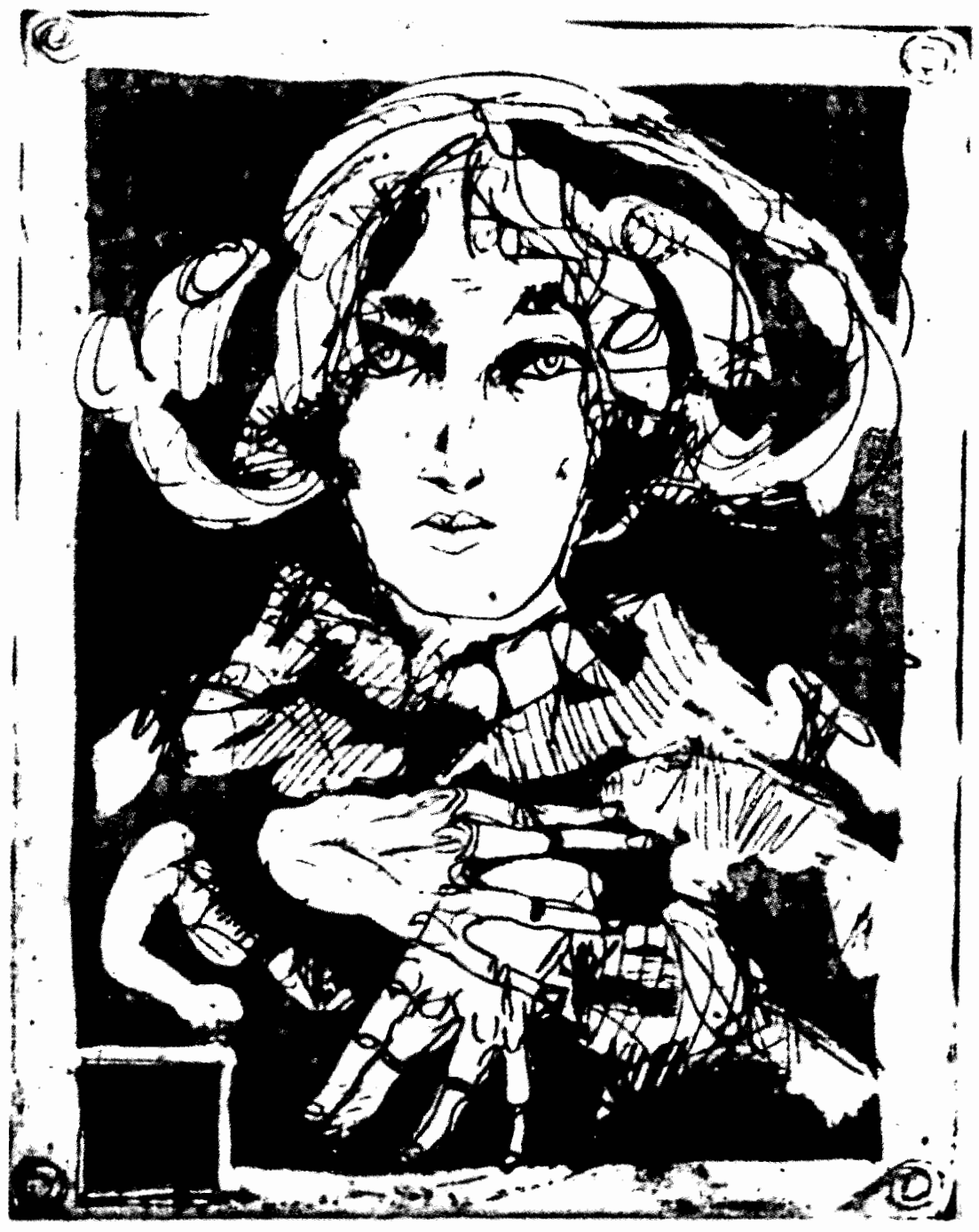


le eran particularmente adversos, optó por proponer una "nueva Argentina" desde un nuevo lugar de la politica: "la plaza del pueblo". Con la nueva lógica que la topología peronista imponía, la política quedaba escindida y el ámbito para el desarrollo de un sistema partidario sumamente reducido. Mientras que el peronismo se legitima en "la plaza" y en la mecánica "movimientista" del justicialismo, el radicalismo -único sobreviviente del periodo anterior-intentará legitimarse en las elecciones. La representación política de la sociedad comenzará a trancurrir por dos canales distintos; la participación política quedará separada de la representación institucional formalizada $y$, en consecuencia, toda posibilidad de consolidación de un sistema partidario maduro quedará bloqueada ante la inexistencia de una única verdadera arena partidaria.

Un cuarto momento histórico de la frustración del sistema partidario argentino se define entonces en torno a la aparición de un nuevo dispositivo político que, de 1955 a 1973 , se articulará mediante la afirmación del principio rector de "la proscripción del peronismo". Nuevamente, durante todo este periodo las posibilidades de recomponer los canales de representación política y de avanzar hacia la reconstrucción de un sistema partidario en Argentina se verán entorpecidas. Y ello por tres vías distintas: por la recurrente amenaza del retorno del movimientismo justicialista, por los brotes de autoritarismo que esta amenaza retroalimenta y por el irresistible atractivo que los votos peronistas -impedidos sistemáticamente de ex- presarse- ejercen sobre los distintos partidos en pugna. El retorno y triunfo de Perón en 1973 nada cambiaron, en realidad, puesto que sólo signaron el ocaso del líder y el inicio de una década de autoritarismo militar que cierra el primer tramo de la historia del "sistema partidario contranatura" que nos ofrece Cavarozzi.

Es recién a partir de 1983 que se define un segundo gran periodo en el que, luego de medio siglo de militarizacion de la política, emerge nuevamente la preocupación por la construcción de un sistema partidario argentino.

La característica fundamental de este nuevo momento radica, según el autor, en la aparición de un "doble desplazamiento de la política", de consecuencias a la vez contradictorias y trascendentes para el papel y las modalidades de funcionamiento de los partidos políticos. El derrumbe estrepitoso de la dictadura militar y el desgaste de todas las formas de organización política no partidarias, determinó la aparición de un nuevo protagonismo partidario y el fortalecimiento del régimen democrático representativo. Sin embargo, por otro lado, la abrupta reducción del tamaño y del poder del Estado que acompañará el retorno de la democracia quitará a estos revitalizados partidos toda posibilidad de reeditar sus viejos patrones de acción partidaria. En otros términos: las viejas prácticas de organizar la acción de los partidos como mediaciones institucionalizadas de extracción y distribución de recursos estatales quedaron rápidamente anacrónicas. Los partidos argentinos, des- 
pués de 80 años, finalmente ubicados en el centro de la escena política, hubieron de descubrir que ya no era posible hacer politica partidaria como antes.

En el año de 1989, el estallido de la hiperinflación, el nuevo triunfo peronista y la cesión anticipada del poder por la Unión Cívica Radical al candidato justicialista permiten hacer la hipótesis de que la política argentina ejecuta un viraje significativo. Agotadas todas las posibilidades de los actores no partidarios y enfrentados los partidos -y en especial el justicialismo- a la necesidad de encarar la gestión de una economía profundamente traumatizada por la hiperinflación, fue necesario innovar. Según Cavarozzi, el establecimiento de nuevas alianzas con partidos políticos como la Unión del Centro Democrático así como una redefinición del lugar de los sectores empresariales dirigentes en el sistema político fueron las modalidades novedosas de estructurar el escenario político de 1989 en adelante. A partir de ese año los acontecimientos posteriores tienden a indicar que el justicialismo ha terminado de aceptar la legitimidad de la arena partidaria con lo que, para el futuro, la nueva centralidad de los partidos políticos argentinos no parece estar abiertamente amenazada.

2. Por su parte, la historia partidaria propuesta por Waldo Ansaldi es, ante todo, la historia de la inexistencia de un verdadero sistema partidario brasileño de 1889 a 1945. A diferencia de lo que parece desprenderse del análisis de los partidos argentinos, la inexistencia de un sistema partidario -e incluso de verdaderos partidos nacionales- en Brasil no es el resultado de un fracaso, puesto que en ningún momento la institucionalización de un sistema partidario parece haber figurado expresamente en la agenda política de Brasil. Más radicalmente, Ia historia de este autor, a diferencia de las otras dos aquí consideradas, es la historia de una "política sin partidos"; o más bien, como el autor nos propone, "un caso de ficción de organización partidaria" de la representación política de la sociedad en su conjunto.

En efecto, en la historia de Brasil, a pesar de la aparente tendencia recurrente del sistema político a una profusa generación de organizaciones llamadas "partidos", en realidad lo que parece verificarse es el predominio aplastante de los esquemas locales y regionales de organización de la representación política y que estos esquemas locales, aun cuando han logrado articularse en un nivel más amplio que el meramente regional, han tendido a asumir casi exclusivamente formas más bien "clientelísticas", "populistas" o "vanguardistas" que modalidades afines a la tradición política de la democracia representativa. La persistente dificultad de identificar la existencia de un verdadero sistema de partidos - e incluso, durante un largo periodo, de partidos políticos propiamente dichos- es reiterada en el trabajo de Víctor Manuel Durand, quien realiza un cuidadoso y pormenorizado inventario de las limitaciones y falencias del funcionamiento de organizaciones partidarias como 
las brasileñas que, a diferencia de las argentinas, ni siquiera parecen conservar perfiles e identidades ideológicos relativamente estables en el largo plazo en el seno de la sociedad civil.

La historia de esta "ficción" de organización partidaria de la política en Brasil que propone Waldo Ansaldi se organiza en torno a la definición de tres grandes momentos políticos: la Republica Velha de 1889-1930, el "proceso de constitucionalización" - entre 1930-1937 y O Estado Novo entre 1937-1945.

En el caso de Brasil, el análisis se inicia con la peculiaridad de que la instauración del régimen republicano no parece estar simultáneamente acompañada por una modificación trascendente de las distintas organizaciones "protopartidarias" que existian bajo el sistema monárquico. $\mathrm{Ni}$ en lo referente a los grandes sectores sociales representados por la escena política partidaria ni en lo referente a la concepción de "la política", que la nueva república hereda del imperio, pueden señalarse discontinuidades significativas.

Por el contrario, desde una óptica partidaria, todo el primer periodo republicano parece caracterizarse más bien por el muy lento y gradual proceso de transformación de los dos viejos protopartidos imperiales en nuevas organizaciones en las que, sin embargo, predominan siempre las viejas tendencias originarias. El partido conservador reencontrará una nueva formulación de su representación de intereses en el seno de los partidos republicanos de São Paulo y Minas Gerais, mientras que el partido liberal hará parcialmente lo propio en los republicanos cariocas y, de manera sui generis, en la emergencia de los nuevos partidos de Rio Grande do Sul. Recién a finales de la década de 1920, con la emergencia de las distintas versiones regionales que adopta el "partido democrático", el universo partidario brasileño parece comenzar a incorporar algunos elementos novedosos.

Con el triunfo de Julio Prestes en 1930, y la explícita ruptura del sistema político do café com leite que este triunfo implicaba, una parte significativa de las grandes tendencias permanentes de ese sistema se verán abruptamente transformadas y una segunda etapa de esta peculiar historia política inicia. La organización del "tenentismo", la emergencia de nuevos sectores urbanos en la escena politica, el llamado "proceso de constitucionalización" y la aparición de la figura de Getúlio Vargas serán algunos de los ejes políticos centrales de este periodo, cuya importancia desborda este breve trecho histórico puesto que lograrán influir decisivamente en la historia política brasileña en el periodo inmediatamente posterior.

A partir de 1937 la escena política brasileña estará claramente ocupada por la consolidación del varguismo y la propuesta de O Estado Novo. Retomando una vieja línea argumentativa, el autor señala que el Estado impulsado por Vargas es sobre todo un gran paso hacia el establecimiento de un Estado moderno y de envergadura nacional que logra "descapturarse" de las viejas redes políticas que, desde la República Velha hasta ese momento, lo habían alineado instrumentalmente 


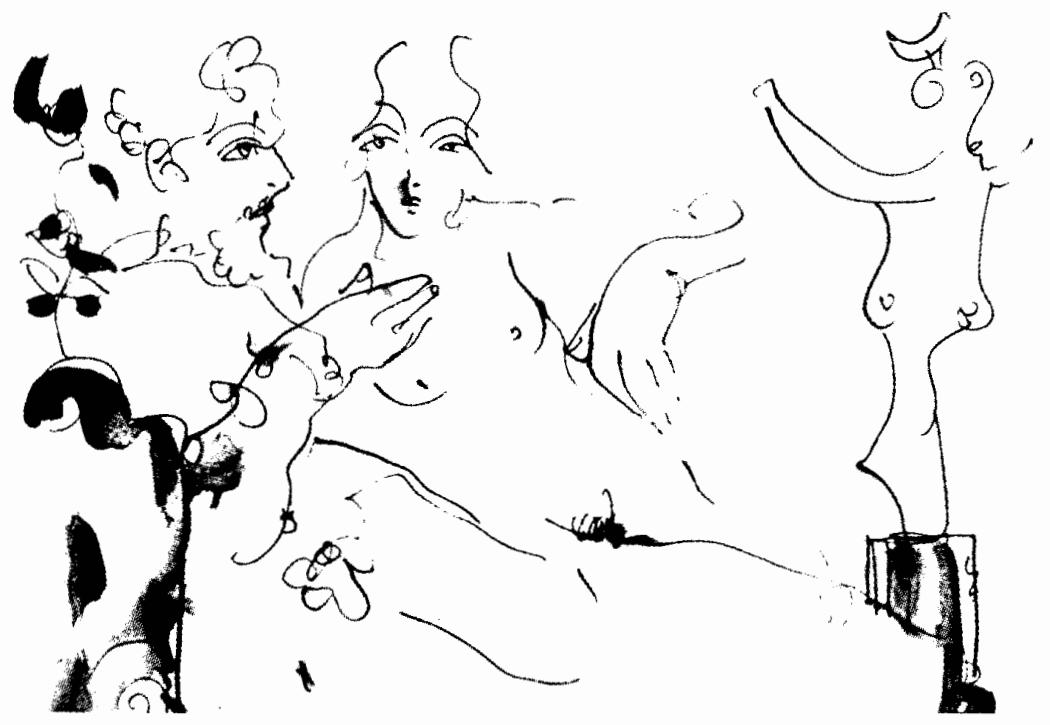

con los intereses de las distintas oligarquías locales y estatales.

Desde la perspectiva estrictamente partidaria, sin embargo, el varguismo aportará muy pocos elementos esperanzadores. La abierta proclividad hacia el corporativismo del régimen y la tendencia a la operacionalización de una "ciudadanía regulada" terminarán cerrando todo espacio para el desarrollo partidario y consolidando un sistema de representación política estatista.

3. Por su parte, en lo referente a la historia partidaria de Uruguay propuesta por Gerardo Caetano, el autor prefiere proponernos la historia de un sistema partidario exitoso que, quizá ante el algo agobiante carácter "partidocrático" del sistema político uruguayo, se encuentra hoy frente a la necesidad de una transformación radical. En la cultura política de ese país, cultura en la que los partidos políticos parecen ocupar un papel preponderante desde los inicios del siglo XIX y de la que, en principio, habrian de emerger las razones profundas de la transformación partidaria en curso, los partidos políticos y sus complejas modalidades de interrelacionamiento ocupan un lugar a la vez ejemplar y problemático. En su trabajo, acordando en general con Caetano sobre la centralidad partidaria del sistema político uruguayo, Gonzalo Varela se interroga sobre lo que pertinentemente llama "el itinerario de construcción de un sistema político moderno" y la po- 
sibilidad de distinguir la existencia de tres momentos decisivos en su desarrollo: el momento de la guerra civil, el de la distribución territorial del poder y el de "la coparticipación".

En el caso de Uruguay, Caetano nos define una organización histórica de largo plazo que tiene como concepto central la idea de la "centralidad partidaria" que caracteriza al sistema político uruguayo desde el establecimiento de sus primeros "patrones tradicionales" hasta la irrupción de la problemática específica de la "agenda reciente".

La periodización implícita de esta historia tiene dos grandes secuencias. Una primera considerada como "de larga duración", que es apenas esbozada al inicio de su intervención y que se organiza en torno a lo que el autor llama "los cuatro grandes conflictos articuladores de la democracia uruguaya". En los albores de la república independiente, con un primer tramo que va de 1830 a 1872 , parece abrirse un primer periodo de pugna entre "doctores" y "caudillos", donde las tentativas de fundar "partidos de ideas" o "partidos de principios" por oposición a las dos viejas divisas partidarias tradicionales campean en las décadas de mediados del siglo XIX. Sin embargo, durante el periodo la acción de los grandes caudillos rige de manera abierta el acontecer político nacional y resulta evidente que, en ningún caso, pudo siquiera comenzar a consolidarse forma partidaria alguna que no incluyese, de una u otra manera, la presencia de las dos divisas tradicionales del país.

El segundo periodo señalado se extiende a partir de 1872 y se establece en torno a la pugna por imponer distintos modelos de ejercicio del poder político durante la cual, ante la debilidad creciente de una dominación política oligárquica en realidad nunca bien establecida en el Uruguay, emerge la tentación militarista. Durante esta pugna, la figura de la "política de coparticipación", ya esbozada a inicios de la década de 1870 , se transforma en el eje articulador de un sistema partidario que, si bien todavía no tiene todas las características de un sistema moderno, comienza ya a perfilarse como uno de los ejemplos más logrados de admisión recíproca entre los dos grandes partidos políticos.

El tercer periodo, caracterizado por la rápida electoralización de la vida política del país y por la emergencia de las primeras preocupaciones relativas a la democracia social, se consolida en la Constitución de 1919 y la subsecuente aprobación de una legislación electoral que marcará el establecimiento definitivo del pacto político que estructura la democracia contemporánea en el Uruguay.

El cuarto periodo que integra la secuencia de larga duración de la historia partidaria uruguaya se caracteriza por la emergencia del conflicto en torno a los modos de participación de actores sociales no-partidarios. Así, ante la emergencia durante la década de 1940 de nuevos actores políticos de corte corporativo -empresarios, sindicatos, etc.-, el sistema uruguayo de partidos deberá enfrentar el desafio que le plantean estas nuevas instancias de representación. La ampliación del Estado y el incremento de la intervención de éste en amplios espa- 
cios de la sociedad civil será, en parte, la respuesta del sistema partidario ante este desafio.

Es de este trance del que arranca una segunda secuencia de la historia política uruguaya -en la que el autor abandona la óptica de largo plazo y nos ofrece una aproximación "micro" de la historia política uruguaya-, a partir del cual es posible entender la crisis del sistema político de ese país de 1955 a la fecha.

El primer periodo de la segunda secuencia se extiende entre 1955 y 1973. Caracterizados como un momento de "corporativización perversa", estos años verán la erosión cada vez más pronunciada de la "centralidad partidaria" del sistema político y la aparición de una profunda crisis en el interior mismo de los mecanismos tradicionales de representación política que culminarán con el golpe de Estado de junio de 1973. "Dictadura y restauración" se titula el análisis del segundo periodo, recortado entre 1973 y 1985 , y que será, paradójicamente, el momento del fracaso de todo intento de reemplazo de los modos partidarios de representación política en general y de los partidos políticos tradicionales en particular.

A modo de conclusión de la segunda secuencia, el autor define un último periodo o "posdictadura" que parece apuntar hacia una transformación interna del sistema de partidos a pesar de que, desde que retornó el régimen democrático en 1985 hasta la fecha, las grandes líneas de aquella política de "permanencias continuativas" definida por Caetano confirma su más amplia vigencia.

\section{POL.́TICAS}

Tomando en consideración lo que podríamos llamar una perspectiva "teórica", los trabajos exploran de manera más o menos explícita -a veces, en realidad, sólo aluden a ellas- una serie de grandes problemáticas generales como la cuestión de las transformaciones del proceso de "inclusión/exclusión" política de la población -que es, simultáneamente, la historia de las modalidades específicas de definición del cuerpo ciudadano en sí mismo-, el problema de la tensión permanente entre la definición de la ciudadanía como "ciudadanía política" y su emergencia como "ciudadanía social" y el siempre problema crítico, en la mayoría de los países de América Latina, del autoritarismo y de la democracia. ${ }^{6}$

Pero de todas las temáticas teóricas que recorren como telón de fondo las historias contenidas en estos trabajos,

\footnotetext{
${ }^{6}$ lin aras de la precisión es ncecsario scinalar que, además de estas grandes temáticas teóricas que están dirceta o indircetamente presentes en los tres ensayos de historias políticas analjzados, es necesario agregar la problemática, especílicamente refericla al caso de Brasil, de lit peculiar conformación espacial del poder politico y de las singulares consecuencias de esa "espacialidad" en la vida política de cse país con general. Más particularmente, cl texto de Ansaldi transcurrirí consistentementc en el borde del análisis de cómo lia conformación política brasileña, con su sistema de agregación regional de intcreses locales y su dificultosa articulación nacional de tendencias regionales repercutirá en la problemática compaginación de un sistema partidario "clásico" que, por lo gencral, presupone modelos de integración nacional menos complcjos, menos cliversos $y$, genciricamente, más "unitarios", homogéneos y centralizadores.
} 
la que seguramente merece la pena de ser especialmente considerada es la de las distintas concepciones de "la política" que subyacen detrás de cada una de estas tres historias. En efecto, a pesar de que los trabajos organizan sus respectivas historias a partir de la definición de un fuerte protagonismo partidista y de que reina una evidente convergencia en lo referente a la preeminencia del enfoque histórico de la cuestión partidaria, en estas historias de los sistemas partidarios latinoamericanos arraigan notorias diferencias en las perspectivas desde las que se considera el concepto de política y, por ende, presumiblemente fuertes divergencias en las maneras mismas de concebirla.

1. En el caso argentino; la política adquiere su significado desde la perspectiva privilegiada del análisis de la inestabilidad institucional. En la primera parte de esta historia de la inestabilidad; la política aparece como parcialmente externa a la realidad partidaria. En una fórmula política que el autor califica de "híbrida", porque no excluye radicalmente la presencia partidaria pero supone la casi sistemática subordinación de los partidos a otro tipo de actores, la política se desarrolla siempre en el terreno estatal y las reglas para la resolución de conflictos parecen ser de carácter esencialmente discrecional. 'Se trata, en este caso, de la historia del fracaso -por lo menos hasta 1983- de la institucionalización de un régimen político, simultáneamente estable y democrático, que logre reemplazar al viejo régimen político oligárquico fe- necido con el advenimiento de la ley Sáenz Peña y sus posteriores consecuencias políticas desde 1912 en adelante.

Este fracaso, aunque es evidentemente materia polémica, no es atribuible a la inexistencia de partidos políticos propiamente dichos - como lo señala el comentario de Aníbal Viguera-; de lo que se trata es de la falencia en el establecimiento de una modalidad sistémica de articulación de la representación política y en el proceso de su adecuada institucionalización. La irrupción del autoritarismo hacia 1930 hará fracasar el primer envión hacia ese objetivo pero, paradójicamente, el periodo que se inicia en ese año tampoco logrará imponer una verdadera restauración conservadora con estabilidad institucional potencial.

La emergencia posterior del peronismo, profundamente orientado contra el establishment, desarrollará la política desde $-y$ la consolidará enuna nueva arena - definida entre el Estado y "la plaza"-, que resultará ser irreconciliable con la política implícita en el discurso democrático y pluralista de los viejos partidos derrotados con la caída de Yrigoyen.

Por ello no es casual que la política argentina, en esta historia de casi ochenta años, sea una política "migrante", en el sentido de que sus ámbitos de ejercicio serán profundamente cambiantes. Aunque, durante la vigencia de la llamada matriz Estadocéntrica (MIC) que Cavarozzi evoca, la estación final de la política será siempre el Estado, sus puntos de partida, en cambio, oscilarán permanente- 
mente entre "el comité partidario", "la plaza del pueblo" y el casi recurrente "cuartel". En la política argentina visualizada por Cavarozzi hay, entonces, una relación -a veces implicita, en otras ocasiones abiertamente establecida- entre esta "ubicuidad" de la política, la falencia en los procesos de institucionalización y el recurrente tema de la inestabilidad política de ese país.

2. La política, en el caso brasileño, parece transcurrir - por lo menos en el periodo histórico cubierto por nuestro autor- en el simultáneamente estrecho y disperso espacio de las negociaciones interelites locales y regionales. Aunque seguramente durante la República Velha ese espacio fue parcialmente parlamentario desde la perspectiva de su sanción institucional, no es menos cierto que se trata de una política que se desarrolla preferentemente entre organizaciones llamadas "partidos políticos" que, las más de las veces, resultan ser simples prolongaciones políticas de sectores dirigentes regionalmente definidos.

Se trata entonces de una política que, más que ejercitarse preferentemente en la portación de la función de representación, parece operar como una "política articuladora" en la que la defensa y promoción de los intereses de las elites regionales y estatal -las únicas efectivamente actuantes en el panorama brasileño analizado- adquieren sentido en la medida en que sean capaces de procesar la "compaginación" de una arena política efectivamente nacional que la sociedad civil brasileña de entonces desconoce o rechaza.

Por ello resulta fundamental para la comprensión de la política brasileña que habita en el texto de Ansaldi destacar dos elementos determinantes. Por un lado, debe recordarse la importancia de la vitalidad de la actividad partidaria de vigencia estatal -en especial en los estados clave como São Paulo, Minas Gerais y Rio Grande do Sul-y, simultáneamente, la recurrencia de la derrota de todos los proyectos de construcción de partidos politicos de envergadura nacional. Por otro lado, es necesario destacar la importancia decisiva de "instituciones" - de alguna manera deberán ser designadas puesto que se trata de prácticas politicas recurrentes que marcaron hondamente el acontecer político brasileño por largo tiempo- como la llamada política do café com leite y la no menos recurrente política dos governadores.

La importancia de ambas modalidades concretas de articular la política a nivel nacional radica en que parecen ser medios para superar lo que se presenta, en el caso de Brasil, como una arena política escindida -o nunca unificada- en la que la política tiende siempre a resultar incompleta o parcial. Mientras que, a nivel estatal, la política se realiza más o menos imperfectamente como "representación" -exclusivamente mediante la existencia de partidos de vigencia regional y la práctica del "coronelismo" al inicio y, posteriormente, con base en la persistencia de los partidos estatales, la continuación del "coronelismo" y la emergencia de grupos mi- 
litares de conformación estatal-, a nivel nacional la política se presenta como mera "articulación" de representaciones políticas forzosamente parciales que sólo se pueden lograr mediante los dos recursos articuladores antes mencionados: la política do café com leite y la política dos governadores.

3. Por su parte, la política en la historia del Uruguay aparece como lo que el autor llama "una política de permanencias"; es decir, una política que parece haber proporcionado las bases para que, tanto el sistema partidario como el sistema político en su conjunto, desde sus momentos formativos hasta la actualidad, se hayan organizado como una "tradición" partidaria. Esta tradición, que el autor llama "una tradición continuativa", no sólo es una tradición resueltamente partidaria. De manera muy nítida los partidos políticos tradicionales uruguayos parecen haber trascendido lo que son las funciones más o menos esperables de todo partido político para transformar la política uruguaya en una "política de partidos de articulación electoral" abiertamente predominante sobre toda otra modalidad de ejercicio de la política.

Esta política de partidos se caracteriza, según el autor, por otorgar a los partidos políticos una intervención decisiva en por lo menos tres dimensiones fundamentales del sistema político uruguayo. En primer lugar, el carácter partidocéntrico de la política uruguaya ha determinado que los partidos políticos tradicionales tengan en realidad el estatuto de sustentos fun- damentales de toda la construcción política democrática del país. En segundo lugar, y dadas su alta capacidad de convocatoria de la sociedad civil y la profundidad de las lealtades políticas que generan en el seno de ésta, los partidos políticos uruguayos parecen constituir un verdadero sistema partidario que se caracteriza por una sorprendente estabilidad. Por último, esta preeminencia partidaria que se ha extendido a lo largo de un periodo tan extenso ha determinado que todo el sistema político se haya articulado de manera casi exclusivamente electoral.

La política partidocéntrica, a diferencia de lo que sucede en los otros dos casos examinados, aparece en el trabajo de Caetano como dotada de una sorprendente capacidad de adaptación $-y$, por ende, como portadora de una clara tendencia a la continuidad-ya que, en los casi 150 años de historia recorridos por el autor, hubo por lo menos tres grandes coyunturas políticas en que esa modalidad de la política fue claramente puesta a prueba y de las que logró recuperarse indemne en lo esencial, aunque transformada en ciertos aspectos.

La primera de ellas tuvo lugar en las primeras décadas del siglo, cuando la emergencia de nuevas modalidades de organización del Estado determinaron el ocaso de la configuración decimonónica y doctoral de la arena política. En efecto, con la Constitución de 1919 el sistema político uruguayo fue capaz de instrumentar los procesos de integración ciudadana que una sociedad en vías de modernización rápida le exigía mediante una consolidación y profundización de la intermediación 


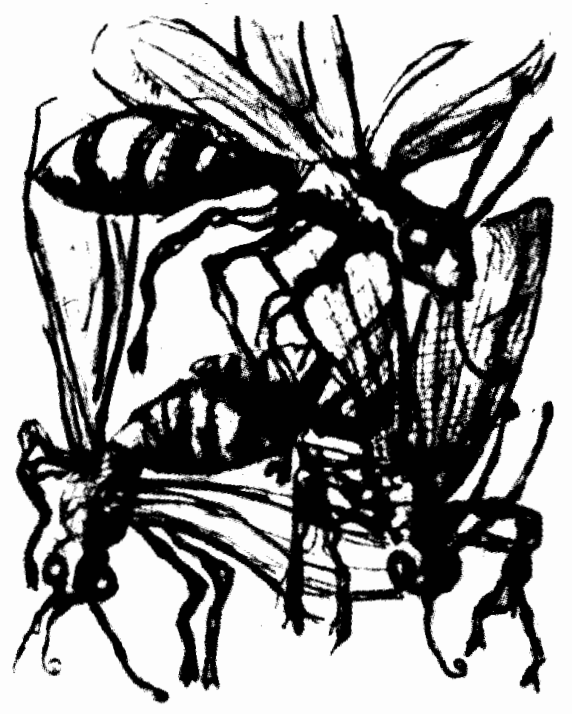

exclusivamente partidaria. Ello significó conseguir que el nuevo Estado inclusivo que se desplegaba contemporáneamente se abstuviese de recorrer los caminos de la interpelación populista y que ese mismo Estado hiciese de los partidos políticos sus interlocutores privilegiados - por no decir únicos-, dejando atrincherados en ámbitos restringidos de la sociedad civil a los distintos procesos de organización social y política que en ese momento se desarrollaron.

Paradójicamente, esto no conspiró contra la función rectora del Estado en ese periodo. Por el contrario, armado de una sólida alianza con los partidos políticos, en la que estos últimos parecen haber funcionado como los "facilitadores" del despliegue estatal, el Estado uruguayo pudo transformarse en lo que el texto llama "el centro imaginario de la unidad social"; es decir en un Estado "centro regulador" que, apoyado en los partidos, logró siempre escapar medianamente ileso de las cerradas redes de intereses de los grupos preeminentes de la sociedad civil.

Esta política de partidos, fortalecida a partir de las primeras décadas del siglo XX por la creciente capacidad política de un Estado cada vez más activo, sufrió hacia mediados de los años cincuenta una segunda prueba decisiva. Entre 1955 y 1973 fueron los partidos políticos los que parecen haber claudicado ante lo que Caetano llama un proceso de "corporativización perversa". Aunque el texto no es 
muy explícito al respecto, la crisis política -ante todo crisis partidariaque se desarrolla a partir de fines de la década de 1950 parece indicar una pérdida de eficacia de los partidos políticos en su papel de organizadores casi monopólicos de la sociedad civil uruguaya. El movimiento sindical, las cámaras empresariales así como una serie de actores extrasistémicos de emergencia coyuntural desecharon los tradicionales carriles partidarios para encauzar las demandas políticas y, en ese envión, arremetieron contra las modalidades establecidas de relacionamiento entre el Estado, los partidos y la sociedad civil.

A pesar de la severidad de una crisis que al desembocar en el establecimiento de una dictadura cívico-militar cuestionó severamente la vigencia de la propia "tradición continuativa" anteriormente constatada, el laborioso proceso de transición hacia la democracia y las modalidades políticas del nuevo régimen democrático que se instaura a partir de 1983 indicaron que, nuevamente, los partidos políticos uruguayos habían logrado recuperar el control de la arena política del país.

La coyuntura actual, a pesar de que por un lado reafirma la vigencia de esa política partidocéntrica que, más allá de coyunturas temporalmente restringidas, parece ser una constante del sistema político uruguayo, indica, por el otro, la aparición de una serie de acontecimientos novedosos que permiten interrogarse sobre los derroteros partidarios futuros.

Aunque la profundidad de los cambios económicos, sociales y políticos sufridos por el Uruguay de 1973 en adelante hacen posiblemente inviable el camino de una restauración estricta de la política de partidos que el país conoció quizá desde los años posteriores a su independencia, no es menos cierto que, para el autor, toda renovación del sistema político uruguayo tiene, como centro neurálgico, una reforma radical de un sistema partidario que parece estar, al menos hasta la fecha, en un acelerado proceso de transición.

Lo que equivale a decir que también hoy, y quizá por largo tiempo, la nueva política que nos depara el Uruguay de mañana habrá de ser, una vez más, una política de partidos.

\section{A MODO DE CONCLUUSIONISS}

Ninguno de los tres trabajos centrales intentan ofrecernos verdaderas conclusiones. Ello es explicable puesto que, como vimos, se trata de ensayos de un talante más histórico que teórico y que aspiran fundamentalmente a procesar la elaboración de reconstrucciones del acontecer partidario y político de sus respectivas realidades nacionales por lo que, en los casos que llevan a conclusiones, ellas sólo apuntan a esbozar una brevísima prospectiva en lo referente al futuro de los partidos políticos en esos países.

En nuestro caso, también corresponde concluir de manera igualmente breve. Los ensayos que hemos trabajado a lo largo de este texto deben ser considerados, ante todo, en el marco de la nueva orientación general de los estudios políticos latinoamericanos 
que mencionamos en nuestra introducción $\mathrm{y}$, en particular, en relación con el creciente papel de los partidos políticos en los procesos de consolidación democrática.

En efecto, en el panorama político latinoamericano actual, considerando que la inestabilidad política, el autoritarismo y la debilidad de los componentes democráticos parecen haber sido altamente recurrentes en los más diversos regímenes políticos latinoamericanos a lo largo del siglo $\mathrm{XX}$, la cuestión de los partidos políticos aparece como decisiva ya que, en el seno de semejante tradición política, para los procesos de consolidación democrática en curso en el continente se abren en realidad muy diversos caminos. En otros términos, los países latinoamericanos están en la coyuntura actual optando entre diversas modalidades posibles para consolidar la democracia.

Aunque la posibilidad de recorrer lo que sería "una vía partidaria" de fortalecimiento de la democracia resultaría ser la más satisfactoria, nada indica que sea efectivamente esta modalidad de consolidación democrática la que termine prevaleciendo. Es por ello que, en lo que a nuestros trabajos se refiere, sus principales virtudes pueden ser analizadas desde una óptica que, además de académica, resulta ser simultáneamente política. El centramiento del interés analítico en la historia de los partidos políticos latinoamericanos y la realización de trabajos como los que hemos reseñado deben ser, en consecuencia, visualizados en el marco de esta ecuación politica de la democracia latinoamericana.
Por imperfectos que resulten ser - tanto en América Latina como en el resto del mundo- los partidos políticos contemporáneos, no es menos cierto que las formas partidarias parecen haber sido, al menos hasta la fecha, las únicas herramientas que se han revelado razonablemente adecuadas para una implantación conjunta y armónica de los cuatro grandes objetivos - ¿correspondería, quizá, decir "ideales"? - perseguidos por las sociedades actuales en materia política: estabilidad, liberalismo, democracia y justicia. En ese sentido no resulta imposible concebir la historia política del siglo XX como una historia cuyos avatares fundamentales se organizan en torno a la búsqueda de la articulación de estos objetivos políticos primordiales. Así, es posible constatar la existencia de una gran cantidad de ejemplos históricos de regímenes políticos latinoamericanos que lograron conjunciones relativamente virtuosas de algunos de estos elementos: estabilidad política y liberalismo caracterizaron muchos de los regímenes políticos de fines del siglo XIX; liberalismo, democracia y, a veces, cierta fugaz estabilidad, tendieron a conjuntarse en algunos países del continente en las primeras décadas del siglo $\mathrm{XX}$; democracia, estabilidad y una intensa retórica en búsqueda de la justicia se hicieron a veces presentes en algunas de las soluciones populistas posteriores a la década de 1930.

Sin embargo, en los únicos ejemplos - por cierto particularmente escasos a nivel universal- en los que se puede discernir con cierto fundamento una tendencia nítida a la afirmación 


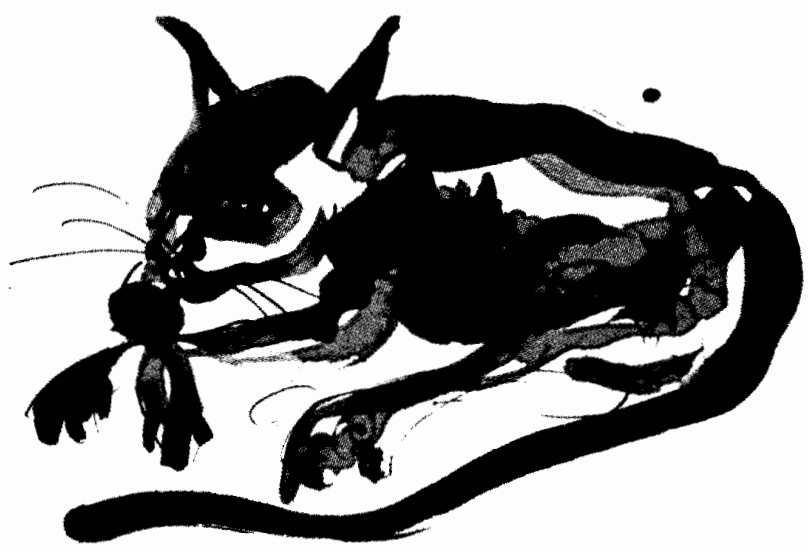

conjunta de estos grandes objetivos políticos antes mencionados, la situación aparece casi siempre asociada a la presencia de partidos políticos fuertes, dotados de verdaderas organizaciones de envergadura nacional, relativamente arraigados en las lealtades políticas de la población y, simultáneamente, estructurados entre sí mediante sistemas partidarios por lo menos medianamente institucionalizados.

No obstante, no se trata de asociar indiscriminadamente la presencia de partidos fuertes y de sólido arraigo con la existencia de una convergencia relativamente armónica hacia los grandes objetivos políticos planteados. La fortaleza partidaria y, más precisamente, la vigencia de estas moda- lidades particulares de la institución partidaria en los sistemas políticos latinoamericanos, resultan ser apenas una primera condición, o condición necesaria, para que la conjunción entre estabilidad, justicia, democracia y liberalismo políticos resulte mínimamente imaginable. Hay en realidad una segunda condición que se requiere -que, quizá de manera por demás optimista, podríamos bautizar como condición suficiente- para que sea posible esta peculiar conjunción. Ella parece radicar en el hecho decisivo de que los partidos políticos y los sistemas de partidos, además de haber reunido los requisitos incluidos en la primera condición, deben haber aceptado, en cualquier caso, la pertinencia de estos objetivos y haber 
transformado la búsqueda sistemática de estos grandes valores en el eje central de su quehacer político.

La sola consideración desapasionada de todos los requisitos implícitos en estas dos condiciones y su comparación con las tumultuosas y fracturadas historias partidarias que hemos analizado, nos indica, ante todo, las dificultades que todavía tendrán que enfrentar las frágiles democracias de la mayor parte de los países latinoamericanos.

\section{BIBLIOGRAFÍ $\Lambda$}

-Bambirra, Vania, El capitalismo dependiente latinoamericano, Siglo XXI Editores, Mćxico, 1974.

- Barros Horcasitas, J. L., J. Hurtado y G. Pérez Fernández. (comps.), Transiciones a la democracia y reforma del Estado en América Lalina, fiscso, México, 1991.

-Cavarozzi, M. y M. A. Garretón, Muerte y resurrección; los partidos políticos en el autoritarismo y las transiciones del Cono Sur, FLACSO, Chilc, 1989.
- Cavarozzi, Marcelo, Más allá de las transiciones a la democracia en América Latina, Centro de Estudios Constitucionales, Madrid, 1991.

-Cotler, Julio, Clases, Estado y nación, Instituto de Estudios Peruanos, Lima, 1978.

-Dutrénit, Silvia y Leonardo Valdés (coords.), El fin de siglo y los partidos políticos en América Lalina, Instituto Mora/uam-I/Conacyt, México, 1995.

-Ianni, Octavio, Populismo y contradicciones de clase en Latinoamérica, Vidiciones Eira, México, 1977.

-Kaplan, Marcos, Formación del Listado nacional en América Latina, Amorrortu Editores, Buenos Aires, 1969.

-Lechner, Norbert, Los patios interiores de la democracia, FCl, Chile, 1990.

-Mayorga, R. A. (coord.), Democracia y gobernabilidad en América Latina, Ce. bem/Nucva Socicdad, La Paz/Caracas, 1992.

-Nun, José, La rebelión del coro, Nucva Visión, Buenos Aires, 1988.

-Pereyra, Carlos, "Estado y socicdad", en Pablo González Casanova y Enrique Florescano (coords.), México hoy, Siglo XXI Eclitores, México, 1979. 